\title{
Commentary: Surgeon versus mesothelioma in a thoracic cage match
}

\author{
Chuong D. Hoang, MD
}

Surgical resection is an important component in the multimodality therapy of malignant pleural mesothelioma (MPM), a surface cancer without cure that is unexpectedly continuing to increase in incidence worldwide. ${ }^{1}$ In properly selected patients, a macroscopic complete resection contributes to improved outcomes and survival. ${ }^{2}$ Such a radical intervention can be associated with significant morbidity and so more routine preoperative identification of patients who have advanced disease that is not resectable is of great importance.

Burt and colleagues ${ }^{3}$ demonstrate, retrospectively, the utility of using a surrogate variable termed thoracic cage volume (TCV) to identify the pathoanatomic scenario of diffuse chest wall invasion (DCWI) by tumor. The 3-dimensional TCV is calculated using commercial software analyzing preoperative chest computed tomography (CT) scan data once a radiologist manually specifies the boundaries of the thorax. For every patient scan, the TCV of each hemithorax is compared. In a subgroup of 24 patients who had DWCI during curative intent surgery, an ipsilateral (to tumor side) TCV decrease $>5 \%$ was closely associated with DWCI. Their anecdotal physical exam observations of chest wall contraction (ie, represented by a smaller TCV value) being linked to DCWI at the time of attempted surgical resection, led the authors to this intriguing association of CT image data and cancer extent (ie, pathologic stage).

Earlier clinical staging efforts in patients with MPM have generally concluded that the imaging modalities of CT,

From the Thoracic Surgery Branch, National Cancer Institute, Bethesda, Md. Disclosures: Author has nothing to disclose with regard to commercial support.

Received for publication Jan 20, 2020; accepted for publication Jan 22, 2020; available ahead of print Feb 29, 2020.

Address for reprints: Chuong D. Hoang, MD, Thoracic Surgery Branch, National Cancer Institute, 10 Center Dr, Mail code 1201, Room 4-3940, Bethesda, MD 20892 (E-mail: chuong.hoang@nih.gov).

J Thorac Cardiovasc Surg 2020;159:2522-3 $0022-5223 / \$ 36.00$

Copyright $₫ 2020$ by The American Association for Thoracic Surgery

https://doi.org/10.1016/j.jtcvs.2020.01.034

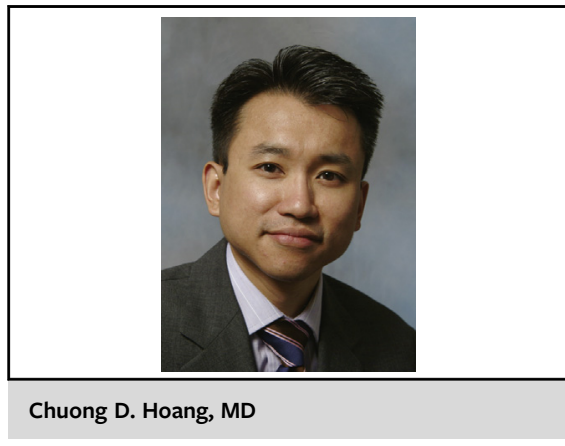

CENTRAL MESSAGE

A relative decreased volume of

the hemithorax as calculated

from CT image data is associated

with extensive chest wall invasion

by mesothelioma and suggests

unresectability.

positron emission tomography, and magnetic resonance imaging are not reliable and consistent enough to establish stage (and thereby resectability), leading to our current standard of extended surgical staging for MPM. ${ }^{4}$

Although in the single prospective study by Patz and colleagues $^{5}$ examining MPM resectability, they suggested that $\mathrm{CT}$ and magnetic resonance imaging of that era (30 years ago) were sensitive enough and provided useful information for surgical decision making. Here, the authors have cleverly extracted readily available biology-associated information, unappreciated by the naked eye, from CT scan image data. These results lend further support to the rapidly emerging field of radiomics that posits the distinctive imaging features of all biologic conditions contain clinically relevant information that can be analyzed by quantitative methods. ${ }^{6}$ Because TCV is a calculated value, in future larger analyses it should be a relatively easy task to ascertain how robust this parameter performs in associating with DCWI and hence unresectability. Furthermore, with a prospectively designed study, it will be possible to determine whether TCV is truly accurate in preoperative prediction.

Burt and colleagues ${ }^{3}$ have developed an elegant method to specifically assess tumor involvement vis-à-vis DCWI along the bony chest wall. This added information is only 
relevant to the subgroup of patients with MPM who otherwise appear to be candidates for surgical resection by routine imaging modalities. A remaining caveat is that their radiologic technique does not explicitly assess the tumor involvement with the diaphragm, mediastinum, or major thoracic structures (eg, the aorta) as part of the determination of resectability. In fact, the authors encountered the situation where a few patients in the larger cohort undergoing operation were deemed not to be candidates for resection due to tumor invasion of other anatomic structures besides the chest wall. Moving forward, TCV assessment could be a useful preoperative parameter complementary to routine imaging that will favorably influence the surgical care of patients with MPM. We eagerly await updates from the authors in this regard.

\section{References}

1. Beckett P, Edwards J, Fennell D, Hubbard R, Woolhouse I, Peake MD. Demographics, management and survival of patients with malignant pleural mesothelioma in the National Lung Cancer Audit in England and Wales. Lung Cancer. 2015; 88:344-8.

2. Kaufman AJ, Flores RM. Surgical treatment of malignant pleural mesothelioma Curr Treat Options Oncol. 2011;12:201-16.

3. Burt BM, Lee H-S, Raghuram AC, Strange C, Mason J, Strange T, et al. Preoperative prediction of unresectability in malignant pleural mesothelioma. J Thorac Cardiovasc Surg. 2020;159:2512-20.e1

4. Rice DC, Erasmus JJ, Stevens CW, Vaporciyan AA, Wu JS, Tsao AS, et al Extended surgical staging for potentially resectable malignant pleural mesothelioma. Ann Thorac Surg. 2005;80:1988-92.

5. Patz EF Jr, Shaffer K, Piwnica-Worms DR, Jochelson M, Sarin S, Sugarbaker DJ, et al. Malignant pleural mesothelioma: value of CT and MR imaging in predicting resectability. AJR Am J Roentgenol. 1992;159:961-6.

6. Gillies RJ, Kinahan PE, Hricak H. Radiomics: images are more than pictures, they are data. Radiology. 2016;278:563-77.
See Article page 2512

\section{Commentary: Know your enemy - Understanding futility in the battle against malignant pleural mesothelioma}

\author{
Andrew E. Giles, MD, MPH, ${ }^{\mathrm{a}}$ and \\ Biniam Kidane, MD, MSc ${ }^{a, b, c}$
}

Malignant pleural mesothelioma (MPM) presents many challenges for patients and physicians battling this difficult disease. It is difficult to stage, challenging to treat surgically, and poorly responsive to adjuvant therapy. Multimodal treatment strategies have flourished as the

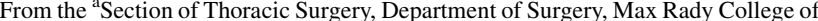
Medicine, ${ }^{b}$ Department of Community Health Sciences, University of Manitoba, Winnipeg, Manitoba, Canada; and ${ }^{c}$ Research Institute in Oncology \& Hematology, Cancer Care Manitoba, Winnipeg, Manitoba, Canada.

Drs Giles and Kidane contributed equally to the conception and writing of this editorial. Drs Giles and Kidane have undertaken final review and approved.

Funding: No funding was received in relation to this work.

Disclosures: Authors have nothing to disclose with regard to commercial support.

Received for publication Jan 5, 2020; revisions received Jan 5, 2020; accepted for publication Jan 5, 2020; available ahead of print Feb 29, 2020.

Address for reprints: Biniam Kidane, MD, MSc, GE-611, 820 Sherbrook St, Health Sciences Centre, Winnipeg, Manitoba R3A 1R9, Canada (E-mail: bkidane@hsc. mb.ca).

J Thorac Cardiovasc Surg 2020;159:2523-4

$0022-5223 / \$ 36.00$

Copyright (C) 2020 by The American Association for Thoracic Surgery

https://doi.org/10.1016/j.jtcvs.2020.01.034
}

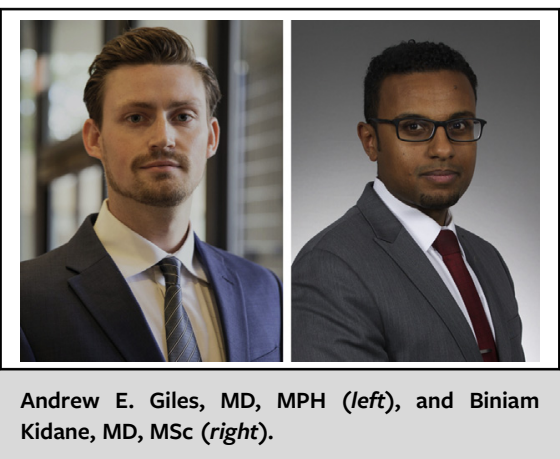

CENTRAL MESSAGE

Novel applications of chest volume analysis may improve prediction of unresectability in malignant pleural mesothelioma. Development and validation of such tools is a promising area of

thoracic progress.

oncology community grapples with these problems. ${ }^{1,2}$ For selected patients with early stage disease and favorable histologic type, surgery can be part of a curative approach ${ }^{3}$; however, surgery can also be a painful and ultimately fruitless undertaking in many patients. ${ }^{4}$ Futile surgery is harmful in many ways; it can reduce quality of life and delay or disqualify patients from receiving other, more appropriate therapies. 